\title{
Review
}

\section{A Possible Mechanism Underlying the Effectiveness of Acupuncture in the Treatment of Drug Addiction}

\author{
Chae Ha Yang ${ }^{1}$, Bong Hyo Lee ${ }^{2}$ and Sung Hoon Sohn ${ }^{2}$ \\ ${ }^{1}$ Department of Physiology and ${ }^{2}$ Department of Acupuncture, Moxibution and Acupointology, College of Oriental \\ Medicine, Daegu Haany University, Daegu, 706-828, South Korea
}

\begin{abstract}
Clinical trials are currently underway to determine the effectiveness of acupuncture in the treatment of drug addiction. While there are still many unanswered questions about the basic mechanisms of acupuncture, some evidence exists to suggest that acupuncture can play an important role in reducing reinforcing effects of abused drugs. The purpose of this article is to critically review these data. The neurochemical and behavioral evidence showed that acupuncture's role in suppressing the reinforcing effects of abused drugs takes place by modulating mesolimbic dopamine neurons. Also, several brain neurotransmitter systems such as serotonin, opioid and amino acids including GABA have been implicated in the modulation of dopamine release by acupuncture. These results provided clear evidence for the biological effects of acupuncture that ultimately may help us to understand how acupuncture can be used to treat abused drugs. Additional research using animal models is of primary importance to understanding the basic mechanism underlying acupuncture's effectiveness in the treatment of drug addiction.
\end{abstract}

Keywords: acupoint-drug abuse-mesolimbic dopamine system-opioid reward system

\section{Introduction}

Acupuncture, arguably the most well-known alternative medicine treatment, has been an important therapy in Eastern countries for thousands of years. Although introduced relatively recently, acupuncture has gained popularity and greater acceptance as a treatment option in Western countries.

In oriental medicine, the human body is considered to be a complex network of intricately related processes played upon by opposing forces (Yin and Yang). Health is viewed as the maintenance of balance and harmony between Yin and Yang, while illness is an expression of unbalance and disharmony between Yin and Yang (1). Acupuncture is an important treatment modality in

For reprints and all correspondence: Chae Ha Yang, Department of Physiology, College of Oriental Medicine, Daegu Haany

University, 165 Sang-Dong, Suseong-Gu, Daegu, 706-828, South Korea. Tel: +82-53-770-2239; Fax: +82-53-770-2278;

E-mail: chyang@dhu.ac.kr manipulating and balancing Yin and Yang. Acupuncture involves the stimulation of specific points on the skin, usually by the insertion of metallic needles; however, related techniques such as manual, electrical or laser stimulation of acupuncture points are also often summarized under this term. In its original form, acupuncture was based on the principles of traditional oriental medicine. In oriental medicine, health is understood in terms of a vital force or energy called 'Qi', a metaphysical concept, which circulates between the organs along hypothesized channels called meridians. On these 'meridians', there are 365 designated acupuncture points that can be used for stimulation through needles or 'moxibustion' to balance and harmonize Yin and Yang by relieving blockages in the flow of 'Qi'. Qi energy must flow in the correct strength and quality through each of these meridians and organs for health to be maintained. The acupuncture points are located along the meridians and provide one means of altering the flow of Qi. Thus, the supposed principle of acupuncture 
in oriental medicine is correcting the unbalanced and disharmonized flow of Qi by stimulating the relevant points on the body surface $(2,3)$. Conformation of acupuncture's role for homeostasis by manipulating and balancing Yin and Yang was shown, when the body's innate homeostatic potentialities are overwhelmed by acute-or chromic-stress conditions (4).

Complementary therapies are widely used throughout the world, but in fact their effectiveness is quite controversial $(5,6)$. Among them, acupuncture is one of the spotlighted treatments on the field of illness which is hard to cure in the modern western medicine. Acupuncture as a therapeutic intervention has been widely practiced for the treatment of many functional disorders including substance abuse and mental illness in Eastern countries through diverse methods such as manual acupuncture, electroacupuncture and acupoint nerve stimulation (7). Importantly, acupuncture has become a standard procedure in many detoxification programs for drugs, worldwide $(8,9)$. While more scientific studies are needed to confirm the efficacy and define the physiological mechanisms of acupuncture, the National Institutes of Health Consensus Development Panel issued a report in 1977 stating 'Acupuncture may be useful as an adjunct treatment or an acceptable alternative or be included in a comprehensive management program' (10). Also, in 1997, a consensus panel issued by the NIH cautiously concluded that acupuncture might be efficacious in the treatment of post-operative and chemotherapy nausea and vomiting, nausea of pregnancy and post-operative dental pain, including drug addiction (11).

Addiction treatment programs increasingly use a combination of conventional and complementary/alternative medicine (CAM) method as acupuncture. Many studies in acupuncture have used auricular acupuncture for the treatment of addictions in patients, stimulating on a 3-4 point including Shenmen auricular point. However, the clinical data obtained from effects of auricular acupuncture for drug addiction have not been consistent. Several works have shown that auricular acupuncture did not provide significant contribution over, and above, that achieved by conventional treatment alone in reduction of alcohol and cocaine use $(12,13)$ and was not more effective than needle insertion at control point in reducing cocaine use (14). The existing data fail to document the benefit of acupuncture in treating cocaine addiction as the sole treatment at this time. However, some evidence exists to suggest that acupuncture can be beneficial in the treatment of cocaine addiction as an adjunctive therapy (13). Importantly, there is considerable evidence to support that electroacupuncture at body points is also particularly effective in alleviating the withdrawal syndrome in heroin addicts $(15,16)$. These findings are intriguing in light of the fact that recent clinical studies have brought the search for the difference between body and auricular points in the efficacy of acupuncture in the treatment of drug addiction.

Only a few experiments using animal models have been performed to determine the basic mechanisms underlying acupuncture's effectiveness in the treatment of drug addiction. Unfortunately, very little is known about the effects of acupuncture in a situation where drugs of abuse are used on a chronic basis and how chronic use of drug effects both neurochemical and behavioral changes. However, it has been generally accepted that acupuncture treatment can contribute to the biochemical balance in the central nervous system and maintenance or recovery of homeostasis $(17,18)$. Additionally, results of some animal studies regarding drug addiction have provided evidence for the involvement of neurotransmitters in the action of acupuncture (19). Additional research using animal models is of primary importance to understanding the basic mechanisms of acupuncture. The present article will explore studies directed at elucidating the neurobiological mechanism of acupuncture on drug addiction with focus on Yin and Yang theory.

\section{Physiological Basis of Drug Addiction}

\section{Role of Dopamine}

The mesolimbic dopamine system originates in the ventral tegmental area (VTA) and projects to regions that include the nucleus accumbens and prefrontal cortex. Dopamine is believed to be the final common pathway for drugs such as cocaine, morphine and alcohol. The neurobiological substrate for self-administration of all addictive drugs by animals and drug abuse in humans is believed to, in some way, involve the dopamine system of the nucleus accumbens, a primitive structure that is one of the brain's important pleasure centers. Dopamine is believed by many to be directly responsible for the exhilarating rush that reinforces the desire to take drugs in drug addicts and plays a pivotal role in the development of drug addiction. These drugs of abuseinduced changes in brain levels of dopamine are associated with feelings of well being and pleasure and provide positive reinforcement; contributing to the continued drug abuse (20-22). Furthermore, repeated drug administration produces sensitization of extracellular dopamine levels in the nucleus accumbens and behavioral sensitization in rats, as evidenced by an enhanced locomotor response and increased dopamine release in brain $(23,24)$. Conversely, withdrawal from chronic drug administration produced a reduction in dopamine outflow in the nucleus accumbens (25-27). As suggested by many studies, drug-induced dopamine depletion in the mesolimbic system may represent the mechanism, at least in part, underlying dysphoria and anhedonia that accompanies drug withdrawal and might 
also contribute to the intense drug craving experienced by addicts $(28,29)$. These withdrawal-negative affects are largely associated with negative reinforcement.

Although it is generally believed that the same neural systems are involved in drug reward and drug-associated learning, there are two different theories that have opposite views on the role of brain reward pathways in mediating drug-seeking behavior. One theory suggests that drug seeking is triggered by drug-like, proponent processes that activate reward pathways in a manner similar to acute effects of drug itself $(30,31)$. Another theory suggests that drug-opposite or opponent processes induce drug seeking by producing a hypofunctional state of reward pathways which leads to dysphoria or anxiety during withdrawal (32). Yin and Yang theory may explain these seemingly opposite proponent and opponent theories underlying drug addiction and relapse to drug seeking. Koob and Moal Le (33) proposed a conceptual framework of allostasis which focused on abnormal changes in reward function that lead to excessive drug taking and drug seeking in prolonged withdrawal. The allostasis model has been proposed for brain changes that occur during the development of addiction process and explains the persistent vulnerability to relapse long after drug taking has ceased. During the course of addiction, counter-adaptive processes such as opponent process that are usually part of normal homeostatic limitation of reward function fails to return to normal range and it is hypothesized to form an allostatic state. The allostasis model shares a similar concept on reward with Yin and Yang theory, from the standpoint of understanding that both theories explain the homeostasis and balance between positive and negative impact on drug addiction.

\section{Modulation of Dopamine Neuron by GABA and Opioids}

The firing activity of dopamine neuron is controlled by the intrinsic activity of the neuron as well as the inhibitory and excitatory input, which it receives from other brain structures as well as from local GABA interneurons in the VTA. GABA can interact with either $\mathrm{GABA}_{\mathrm{A}}$ or $\mathrm{GABA}_{\mathrm{B}}$ receptors present in the VTA. While GABAergic neurons are known to dampen dopamine neurons via inhibitory $\mathrm{GABA}_{\mathrm{A}}$ or $\mathrm{GABA}_{\mathrm{B}}$ receptors in the VTA dopamine neurons $(34,35)$, recent findings suggest that $\mathrm{GABA}_{\mathrm{B}}$ receptors play a predominant role in attenuating the reinforcing effects of the drugs through a modulation of dopamine transmission. For example, it has been shown that the $\mathrm{GABA}_{\mathrm{B}}$ antagonist SCH 50911 blocked gamma-vinyl GABA's inhibition of cocaineinduced increases in dopamine in the nucleus accumbens (36). A similar conclusion was obtained in another study in which $\mathrm{GABA}_{\mathrm{B}}$ receptor agonist baclofen dose dependently reduced heroin-induced dopamine release in the nucleus accumbens and inhibited heroin self-administration behavior (37). Therefore, it is highly likely that
$\mathrm{GABA}_{B}$ receptor stimulation is sufficient to dampen nucleus accumbens dopamine release induced by abused drugs. Chronic cocaine or amphetamine is associated with altered $\mathrm{GABA}_{\mathrm{B}}$ receptor function after withdrawal (38). Importantly, the observed increase in $\mathrm{GABA}_{\mathrm{B}}$ heteroreceptor function would be expected to lead to decreased dopamine and glutamate release in the VTA, and may therefore contribute to the reward deficits associated with psychostimulant withdrawal (38). Moreover, chronic administration of ethanol enhanced the baseline activity of VTA GABA neurons underlying the decrease in accumbal dopamine release associated with withdrawal from chronic ethanol (39). It has been shown that probability of GABA release in the VTA area is increased during withdrawal from morphine (40). In contrast, chronic exposure to cocaine decreased the functional coupling of $\mathrm{GABA}_{\mathrm{B}}$ receptors to G-proteins in the VTA in rats, suggesting that cocaine sensitization implicates the enhanced extracellular dopamine levels in the nucleus accumbens (41). There is some direct support for this finding in studies of in vivo microdialysis showing that endogenous GABA release was reduced in the striatum of rats sensitized to cocaine (42). Taken together, these results suggest that neurochemical and behavioral sensitization may imply a decreased ability of $\mathrm{GABA}_{\mathrm{B}}$ receptors to inhibit dopaminergic activity.

Activation of $\mu$ - and $\kappa$-opioid receptors is known to exert opposite modulation of dopamine neuron in the mesolimbic dopamine system $(43,44)$. The $\mu$-opioid receptors are selectively expressed on inhibitory GABA interneurons in the VTA. Activation of $\mu$-receptors hyperpolarizes these GABAergic neurons, causing a disinhibition of the dopamine neurons (45). As a consequence, this leads to the increased accumbal dopamine release. Conversely, $\kappa$-receptor is located on presynaptic dopaminergic nerve terminals in the nucleus accumbens. The $\kappa$-receptor agonist inhibits the dopaminergic neuron directly, resulting in the decrease of accumbal dopamine release (46). Supporting the notion that suppression of GABAergic input onto dopaminergic neurons in the VTA contributes to $\mu$-opioid receptor modulation of cocaine reinforcement, $\mu$-opioid receptor knockout mice showed the reduced cocaine selfadministration and increased GABAergic input to VTA dopaminergic neurons (47). A role for $\kappa$-receptor in dopamine release in the nucleus accumbens was extended by the observation that inhibition of $\kappa$-opioid receptor by $\kappa$-opioid receptor knockout and the $\kappa$-opioid receptor antagonist norbinaltorphimine produced ethanol-induced elevation of extracellular dopamine in the nucleus accumbens, respectively $(48,49)$. Also, recent work has shown that blockade of $\kappa$-opioid receptor increased alcohol drinking in two bottle choice paradigm, suggesting that $\kappa$-opioid receptor may be particularly important for the blockade of the reinforcing effect of ethanol via inhibition of dopaminergic neuron (50). 


\section{A Role for Brain Neurotransmitters in the Action of Acupuncture}

All studies measuring neurochemical responses to acupuncture provided evidence for the biological effects of acupuncture that ultimately may help to understand how acupuncture can be used to treat disease. Moreover, in a more general sense, these results suggest that acupuncture can correct reversible malfunctions of the body by direct activation of brain pathways and thus contribute to the biochemical balance in the central nervous system by regulating neurotransmitters that control health and disease. The discovery of the central endorphin system was a prominent step toward understanding the analgesic effect of acupuncture $(51,52)$. It is now well established that endorphinergic neurons in the hypothalamus projecting to the dosal raphe nucleus and periaqueductal gray matter of the mesencephalon are primarily responsible for acupuncture analgesia (53). Additionally, other brain areas such as the nucleus accumbens, with interconnections to the descending pathway from the hypothalamus to the dorsal raphe nucleus and periaqueductal gray matter, might also mediate opioid- and acupuncture-induced analgesia $(54,55)$. In the nucleus accumbens, drugs of abuse act to produce a large increase in dopamine that has long been associated with addictive behavior (56). The descending antinoceptive pathway from the hypothalamus appears to depend on the activation of the anterolateral tract by acupuncture (57). Also, several brain neurotransmitter systems such as serotonin, catecholamines and amino acids including GABA have been implicated in the analgesic effects of acupuncture (58).

Although few experiments have investigated the effect of acupuncture on GABAergic neuron, GABA-related studies provided evidence that acupuncture stimulation may produce the inhibitory effect via GABAergic neuron. For example, it has been shown that electroacupuncture exerted depressor effect by inhibition of the sympathetic nervous system and this effect was mediated through GABA in the rostral ventrolateral medulla. This inhibitory effect via GABAergic neuron was reversed with injection of GABA antagonist $(59,60)$. GABA has also been implicated in the therapeutic effect of cerebral ischemia by electroacupuncture using middle cerebral artery occlusion (MCAO) rats. Electroacupuncture effectively reduced infarct area in the cerebral cortex and hippocampus and increased GABA immunoreactivity. Inhibition of infarction by electroacupuncture was completely prevented by a GABA receptor's antagonist (61).

With regard to serotonin, microdialysis study showed that acupuncture at bilateral Shenshu acupoints significantly increased serotonin release in the rat nucleus accumbens (62). The authors suggested the possibility that acupuncture affect the reward system pathway of the brain by activation of serotonergic neurons. Further support for a role of acupuncture in regulating brain serotonin is the observation that electroacupuncture prevented restraint-induced decreases in serotonin levels in the nucleus accumbens (63). Serotonin has long been hypothesized to have a role in mediating the efficacy of acupuncture in the treatment of drug withdrawal (64). Considerable evidence showed marked differences between the alcohol-preferring rats and normal rats in that the alcohol-preferring rats have fewer serotonin neurons and higher levels of enkephalin in the hypothalamus, fewer GABA neurons, lower dopamine release and dopamine D2 receptors in the nucleus accumbens (65-68). Based on these observations, it was postulated that chronic exposure to drugs might cause 'reward deficiency syndrome' resulting from a basal dysfunction of brain reward dopamine function. These authors proposed that activation of serotonin neurons in the hypothalamus induces met-enkephalin release in the VTA, and as a consequence, GABA neurons in the VTA are inhibited, thereby increasing dopamine release in the nucleus accumbens (69). This proposal, combined with the finding that acupuncture activates the descending serotonergic pathways via the anterolateral tract (57), have suggested that acupuncture may have a role in normalizing the release of dopamine via serotonin neurons in the hypothalamus (64).

\section{Acupuncture and the Negative Reinforcing Effect of Abused Drugs}

\section{Role of the Mesolimbic Dopamine System in Acupuncture}

Although there is a lack of well-controlled experiments investigating the effect of acupuncture on drug abuse, including ethanol, a few studies using animal models have provided evidence that acupuncture can play an important role in reducing negative reinforcing effects of drug.

Electroacupuncture at the specific point ST36 effectively reduced the increase in alcohol-drinking behavior and enhanced the striatal dopamine level in rats challenged with immobilization stress (70). While ethanol has diverse effects in the brain, ethanol has been shown to increase the firing rates of mesolimbic dopamine neurons by modulating $\mathrm{GABA}_{\mathrm{A}}$ receptors located on GABAergic neurons in the VTA (71). Ethanol has stimulatory, euphoric, sedation, anxiolytic and muscle relaxant effects. Even though all these diverse effects probably cannot be related to one specific single neurotransmitter, dopamine seems to be involved in most of the effects. During ethanol withdrawal, brain stimulation reward thresholds were elevated compared to pre-drug baseline (72). This elevation in reward threshold may reflect an anhedonia state and as such it may be homologous to the anhedonia reported by 
alcohol-dependent patients $(73,74)$. A likely neurochemical mechanism involved in this withdrawal state would be some hypoactivity of dopamine functioning. It has also been shown that withdrawal from chronic ethanol administration can produce a reduction in dopamine outflow in the nucleus accumbens (75). Based on the earlier facts, these results, combined with observations of dopamine levels in the striatum, suggest that the suppression of alcohol-drinking behavior by electroacupuncture may be mediated by the increase of striatal dopamine levels.

Recent studies have shown that acupuncture attenuated alcohol withdrawal syndrome and Fos-like immunoreactivity (FLI) in the striatum and the nucleus accumbens core of rats. During 3 days of cessation following chronic administration of ethanol, rats showed a significant increase in alcohol withdrawal syndrome, such as hypermotility, tail rigidity, grooming and tremor and increase in FLI in the dopamine terminal areas in the brain, reflecting the expected increases in neuronal excitability. Treatment of acupuncture at Zusanli or Sanyinjiao points during withdrawal period inhibited AWS and also prevented the expected increase in FLI of rats exposed to chronic ethanol. These results suggest that acupuncture may be effective in suppressing alcohol withdrawal syndrome by modulating post-synaptic neural activation in the striatum and nucleus accumbens core (76). Similar to these results, a recent study showed that electroacupuncture decreased both c-Fos gene expression in the central nucleus of the amygdala and withdrawal signs in morphine-withdrawn rats (77). Amygdala and nucleus accumbens play an important role for the motivational effect of opiate withdrawal. Given that the increase of c-Fos gene expression in the central nucleus of amygdala is associated with the negative motivational impact on drug addiction, one possibility is that acupuncture could help to normalize neuronal activation and thereby reverse withdrawal signs.

\section{Acupuncture and Cerebral Endogenous Opioid System}

The 'Incentive-sensitization theory' proposes that enhanced mesocorticolimbic dopamine neurotransmission is currently recognized as a common target of the dependence-producing properties of opioids, psychostimulants and alcohol (78). Previous work has suggested cerebral $\beta$-endorphin system may be involved in reward. Additionally, cerebral $\beta$-endorphin originates in the arcuate nucleus of the mediobasal hypothalamus and projects to limbic structures such as the VTA and the nucleus accumbens, seems to be responsible for the reinforcing effects of abused drugs (79). A hypothetical model has been proposed for possible interactions between the endogenous opioid reward system and the release of dopamine from the nucleus accumbens. VTA GABA interneurons connect to VTA dopamine neurons

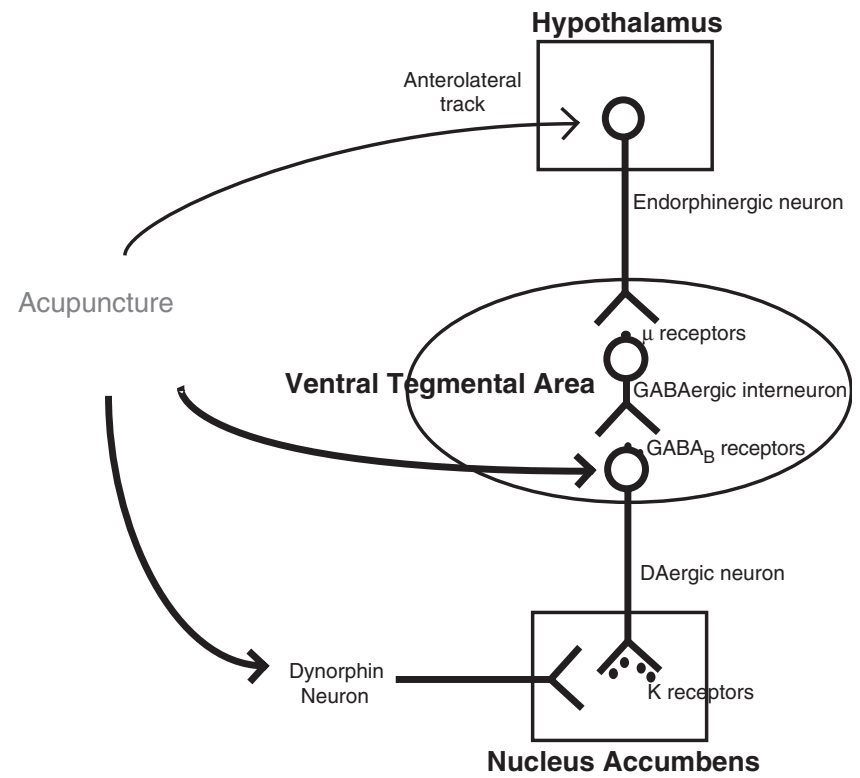

Figure 1. A hypothetical model of possible bidirectional effects of acupuncture on dopamine release in the nucleus accumbens. In positive reinforcement, acupuncture treatment activates $\mathrm{GABA}_{\mathrm{B}}$ receptors on the dopamine cell bodies, resulting in a decrease of dopamine release in the nucleus accumbens through the inhibition of dopaminergic neurons; additionally, acupuncture activates presynaptic $\kappa$-opioid receptors in the nucleus accumbens through dynorphin neurons, resulting in a decrease of dopamine release in the nucleus accumbens. In negative reinforcement, acupuncture treatment stimulates enkephalin neurons in the hypothalamus, such that methionine-enkephalin released in the VTA interacts with $\mu$-opioid receptors to inhibit VTA GABAergic interneurons, inducing the disinhibition of dopaminergic neurons and thus, eventually increases the dopamine release in the nucleus accumbens.

and likely inhibit them. Activation of presynaptic $\mu$-opioid receptors on these GABAergic interneurons decreases the firing rate of VTA GABA neurons, leading to an increase in release of dopamine in the nucleus accumbens, whereas presynaptic $\kappa$-opioid receptors in the nucleus accumbens directly inhibit dopamine release in the nucleus accumbens. $\beta$-endorphin released from fibers ascending from the arcuate nucleus of the hypothalamus stimulates $\mu$-receptors in the VTA, thereby disinhibiting VTA dopamine neurons. Also, it activates $\delta$-opioid receptors in the nucleus accumbens. Thus, $\beta$-endorphin increases dopamine release in the nucleus accumbens (Fig. 1) (80). Several experiments have investigated the effect of electroacupuncture on endogenous opioid system. These opioid-related studies, using animal models, have provided evidence that low-frequency electroacupuncture can activate enkephalinergic and $\beta$-endorphinergic neurons in the nucleus arcuatus of the hypothalamus $(81,82)$. Accordingly, it seems reasonable to propose that electroacupuncture may help to enhance the release of dopamine in the nucleus accumbens via $\delta$-opioid receptors in the nucleus accumbens as well as $\mu$-receptors in the VTA. In addition, there is an important neurochemical evidence that acupuncture 
treatment directly affects the mesolimbic dopamine system. Acupuncture treatment at the specific acupoints Shenmen (HT7) significantly prevented a decrease of extracellular dopamine levels in the nucleus accumbens after withdrawal from chronic ethanol administration, with an accumbal dopamine concentration restored to approximately $90 \%$ of that of naive animal (83). Given chronic ethanol-induced dopamine depletion in the mesolimbic system is linked to the dysphoria and anhedonia that often accompanies ethanol withdrawal (84), acupuncture may play a role in relieving withdrawal syndrome and help to prevent compulsive drug-seeking behavior and relapse.

Animal models for the acute reinforcing effects of abused drugs have included measures of preference for the environment paired with drug administration (conditioned place preference; CPP). Further support for a role of brain $\beta$-endorphin is the observation that lowfrequency electroacupuncture reduced morphine-induced place preference in rats and this effect was reversed by pretreatment of opioid receptor antagonist naloxone at a small dose which is sufficient to block the opioid $\mu$ and $\delta$, but not the $\kappa$, receptors (85). The authors suggested that $\mu$-opioid receptor might be involved in acupuncture's role in suppressing the negative reinforcing effect of morphine. In this study, since CPP paradigm was carried out $24 \mathrm{~h}$ after the last daily injection, the negative stimulus effects of acute morphine withdrawal may be responsible for the preference to the drug-pairing environment. Thus, it is possible that electroacupuncture reduces the negative stimulus effects by activation of dopamine release through $\beta$-endorphinergic and enkephalinergic neurons in the brain, especially in the arcuate nucleus. On the other hand, one behavioral study has indicated that highfrequency electroacupuncture suppressed the naloxoneinduced morphine withdrawal syndrome and this effect was reversed by pretreatment with dynorphin A antibody or $\kappa$-receptor antagonist (86).

The neuropharmacological data reviewed earlier, provide some evidence for the action of the endogenous opioid peptides in acupuncture analgesia. On the basis of these and other findings that low-frequency electroacupuncture facilitates the release of $\beta$-endorphin and enkephalin in the CNS, whereas high-frequency electroacupuncture produced an increase in dynorphin release $(87,88)$, it has been expected that low-frequency electroacupuncture can play a predominant role in attenuating withdrawal syndrome by activating the $\beta$-endorphinergic and enkephalinergic neurons. However, high-frequency electroacupuncture was more effective in suppressing morphine withdrawal syndrome compared to lowfrequency electroacupuncture (89). The exact neurochemical mechanisms mediating the suppressive effect of high-frequency electroacupuncture on withdrawal syndrome is unknown but these results suggest the possibility that electroacupuncture's role in suppressing the morphine withdrawal syndrome takes place by activating the $\mathrm{k}$-opioid receptor and dynorphin release. To summarize the research described earlier, lowfrequency electroacupuncture appears to play a critical role in attenuating the motivational aspects of drug withdrawal, while high-frequency electroacupuncture may be most effective in reducing withdrawal symptoms.

\section{Acupuncture and the Positive Reinforcing Effect of Abused Drugs}

\section{Role of к-opioid Receptor in Acupuncture}

A number of studies with rats have shown that acupuncture attenuates rewarding effects induced by drugs of abuse. Recent work using injections of selective opioid receptor antagonists has shown that $\kappa$-receptor may be particularly important for the inhibitory effect of high-frequency electroacupuncture on the expression of morphine-induced CPP and cocaine-induced CPP $(90,91)$. High-frequency electroacupuncture increases dynorphin release to interact with $\kappa$-receptor in brain (92). A similar observation was obtained in another study in which highfrequency electroacupuncture enhanced the expression of mRNA encoding predynorphin in brain (93). Recent studies have demonstrated that dynorphin causes the decrease in dopamine release within the nucleus accumbens through an action on $\kappa$-opioid receptors that are located on presynaptic dopaminergic nerve terminals in this region $(93,94)$. Furthermore, behavioral studies reported that $\kappa$-opioid receptor agonists decrease cocaine and heroin self-administration $(95,96)$. Therefore, it has been suggested that high-frequency electroacupuncture stimulation is sufficient to dampen morphine-induced CPP through $\kappa$-opioid receptor. Roles for enkephalin and dynorphin in the mechanisms underlying the inhibitory effect of electroacupuncture has been replicated using morphine-induced CPP and reinstatement of extinguished CPP (97). Preproenkephalin or preprodynorphin mRNA levels in the nucleus accumbens were increased, respectively, in rats shown to suppress morphine-induced CPP and reinstatement of extinguished CPP after low- or high-frequency electroacupuncture.

\section{Inhibition of Dopamine Release by Acupuncture}

There is evidence that the enhancement of dopamine transmission in the nucleus accumbens induced by all addictive drugs is linked to its reinforcing properties and may be implicated in the development of behavioral sensitization $(98,99)$. This persistent phenomenon, referred to by some as sensitization, is thought to play a major role in magnifying the positive-reinforcing properties of a subsequent drug challenge and represent the mechanism, at least in part, underlying the 
reinstatement of drug-seeking behavior (100). Thus, there is lot of interest in gaining a better understanding of how acupuncture works in the brain to influence addictive behaviors. Few studies were designed to investigate the effect of acupuncture on extracellular dopamine levels using in vivo microdialysis and behavioral changes in rats treated by repeated drugs, including morphine and alcohol after drug withdrawal followed by drug challenge. Results showed that systemic challenge with drug produced neurochemical and behavioral sensitization indicating a much larger increase in dopamine and behavioral activity compared to saline-pretreated rats. Most importantly, these results demonstrated that even brief (1 min) acupuncture treatments prevented to a great extent, drug-induced elevation in dopamine levels in the nucleus accumbens and also reduced the amount of drug-induced behavioral hyperactivity $(19,83)$. In view of the fact that enhanced dopamine transmission in the nucleus accumbens induced by all addictive drugs has long been associated with addictive behaviors, these results suggest that reduction in behavioral activity by acupuncture may be mediated by attenuation of dopamine release and neuronal activity in the nucleus accumbens. Moreover, in a more general sense these results suggest that minimizing sensitization may be one of mechanisms whereby acupuncture reduces drug craving in addicts.

Fewer studies have been performed to determine the basic mechanism underlying acupuncture's effectiveness in reducing dopamine release induced by the drugs. One study used rats to investigate the possible mechanism of acupuncture on the $\mathrm{GABA}_{\mathrm{B}}$ pathway. Rats were administered with the highly selective $\mathrm{GABA}_{\mathrm{B}}$ antagonist $\mathrm{SCH}$ 50911 prior to an intraperitoneal injection of ethanol. Immediately after ethanol treatment, acupuncture was administered for $1 \mathrm{~min}$. Acupuncture at the specific acupoint HT7, but not at control points (PC6 or tail) significantly decreased dopamine release in the nucleus accumbens. Inhibition of dopamine release by acupuncture was completely prevented by SCH 50911 (101). GABAergic neurons are known to dampen dopamine neurons via inhibitory $\mathrm{GABA}_{\mathrm{B}}$ receptors in the mesolimbic dopamine system (102). Recently, the $\mathrm{GABA}_{\mathrm{B}}$ receptor agonist reduced reinforcing properties of ethanol (103). These earlier-mentioned results suggest that stimulation of specific acupoints inhibits ethanol-induced dopamine release by modulating $\mathrm{GABA}_{\mathrm{B}}$ activity and implies that acupuncture may be effective in blocking the reinforcing effects of ethanol (Fig. 1).

As with cocaine, amphetamines and morphine, addiction to nicotine is believed to result from increased release of dopamine in the region of nucleus acumbens $(104,105)$. One study reported the effect of acupuncture on behavioral locomotor activity and c-fos expression in the nucleus accumbens and striatum utilizing the immunocytochemical detection of the Fos protein in nicotine-sensitized rats. Similar to morphine or ethanolsensitized rats, acupuncture significantly attenuated expected increase in nicotine-induced locomotor activity and FLI in the nucleus accumbens and striatum to subsequent nicotine challenge (106). These findings suggest that acupuncture produces a therapeutic effect on nicotine addiction, possibly by modulating postsynaptic neuronal activity in the nucleus accumbens and the striatum.

\section{Conclusion}

Clinical trials are currently underway to determine the effectiveness of acupuncture in treating drug addiction $(15,107)$. Yet, there are still many unanswered questions about the basic mechanisms of acupuncture. Additional research using animal models is of primary importance in understanding the basic mechanisms of acupuncture. Chronic exposure to drugs of abuse produces a withdrawal state as reflected in increases in brain reward thresholds, and this change in reward threshold appears in be opposite to actions of the drug administered acutely. These opposite proponent and opponent processes during the development of drug addiction may contribute to the intense drug craving experienced by addicts. Based largely on animal self-administration, the reinforcing effects of drugs have been linked to central dopamine activity in the mesolimbic dopamine system. While little is known about the basic mechanism of acupuncture in treating drug addiction, the neurochemical and behavioral data reviewed earlier showed that acupuncture directly or indirectly affects the mesolimbic dopamine system. These results suggest that acupuncture helps to maintain the homeostasis and balance between positive and negative processes involved in drug addiction. Moreover, in a more general sense, these results suggest that acupuncture can be used as a therapeutic intervention for correcting reversible malfunction of the body by directing brain pathways and thus contributes to balance in the central nervous system by regulating neurotransmitters. Future studies should determine if acupuncture therapy can influence any of the other neurotransmitters (GABA and glutamate) believed to play a role in regulating dopamine release. It would also be interesting to assess the effect of acupuncture on drug reward thresholds in animals trained to self-administer drugs of abuse.

\section{Acknowledgements}

The authors are grateful to Mr George Smith for the language editing of the manuscript. This work was supported by a grant (R12-2003-002-03001-0) from the basic research program of the Ministry of Commerce, Industry and Energy, Korea. 


\section{References}

1. Dale R. The origins and future of acupuncture. Am $J$ Acupunct 1982;10:101-20.

2. George AU, Han SP, Han JS. Elecroacupuncture: mechanisms and clinical application. Soc Biol Psychiatry 1998;44:129-38.

3. Vickers A, Wilson P, Kleijnen J. Acupuncture. Qual Saf Health Care 2002;11:92-7.

4. Walling A. Therapeutic modulation of the psychoneuroimmune system by medical acupuncture creates enhanced feelings of wellbeing. J Am Acad Nurse Pract 2006;18:135-43.

5. Eisenberg DM, Davis RB, Ettner SL, Appel S, Wilkey S, Van Rompay M, et al. Trends in alternative medicine use in the United States, 1990-1997: results of a follow-up national survey. JAMA 1998;280:1569-75.

6. Harris P, Rees R. The prevalence of complementary and alternative medicine use among the general popluation: a systematic review of the literature. Complement Ther Med 2000;8:88-96.

7. Han JS, Trachtenberg AI, Lowinson JH. Acupuncture. In: Lowinson JH, Ruiz P, Millman RB, Langrod JG (eds). Substance Abuse, A Comprehensive textbook. Philadelphia: PA, 2005.

8. Avants SK, Margolin A, Chang P, Kosten TR, Birch S. Acupuncture for the treatment of cocaine addiction: investigation of a needle puncture control. J Subst Abuse Treat 1995;12:195-205.

9. Shwartz M, Saitz R, Mulvey K, Brannigan P. The value of acupuncture detoxification programs in a substance abuse treatment system. J Subst Abuse Treat 1999;17:305-12.

10. Anonymous. Acupuncture. NIH consensus statement. JAMA 1998;280:1518-24

11. Anonymous. Acupuncture. NIH consensus statement. 1997;15:1-34.

12. Bullock ML, Kiresuk TJ, Sherman RE, Lenz SK, Culliton PD, Boucher TA, et al. A large randomized placebo controlled study of auricular acupuncture for alcohol dependence. J Subst Abuse Treat 2002;22:71-7.

13. Kim YH, Schiff E, Waalen J, Hovell M. Efficacy of acupuncture for treating cocaine addiction: a review paper. $J$ Addict Dis 2005;24:11-132.

14. Margolin A, Kleber HD, Avants SK, Konefal J, Gawin F, Stark E, et al. Acupuncture for the treatment of cocaine addiction: a randomized controlled trial. JAMA 2002;287:55-63.

15. Zeng X, Lei L, Lu Y, Wang Z. Treatment of heroinism with acupuncture at points of the Du Channel. J Tradit Chin Med 2005;25:166-70.

16. Zhang B, Luo F, Liu C. Treatment of 121 heroin addicts with Han's acupoint nerve stimulator. Zhonguo Zhong $\mathrm{Xi}$ Yi Jie $\mathrm{He} \mathrm{Za}$ Zhi 2000;20:593-5.

17. Zhao CH, Stillman MJ, Rozen TD. Traditional and evidence-based acupuncture in headache management: theory, mechanism, and practice. Headache 2005;45:716-30.

18. Otto KC. Acupuncture and substance abuse: a synopsis, with indications for further research. Am $J$ Addict 2003;12:43-51.

19. Kim MR, Kim SJ, Lyu YS, Kim SH, Lee YK, Kim TH, et al. Effect of acupuncture on behavioral hyperactivity and dopamine release in the nucleus accumbens in rats sensitized to morphine. Neurosci Lett 2005;387:17-21.

20. Weiss F, Paulus MP, Lorang MT, Koob GF. Increases in extracellular dopamine in the nucleus accumbens by cocaine are inversely related to basal levels: effects of acute and repeated administration. J Neurosci 1992;12:4372-80

21. Carrelli RM, Deadwyler SA. Dose dependent transition in nucleus accumbens cell firing and behavioral responding during cocaine selfadministration sessions in rats. $J$ Pharmacol Exp Ther 1996;277:385-93.

22. Peoples LL, Uzwiak AJ, Guyette FX, West MO. Tonic inhibition of single nucleus accumbens neurons in the rat: a predominant but not exclusive firing pattern induced by cocaine self-administration sessions. Neuroscience 1998;86:13-22.

23. Nestby P, Vanderschuren LJ, De Vries TJ, Hogenboom F, Wardehm G, Mulder AH, et al. Ethanol, like psychostimulants and morphine, causes long-lasting hyperactivity of dopamine and acetylcholine neurons of rat nucleus accumbens: possible role in behavioral sensitization. Psychopharmacol 1997;133:69-76.
24. Cadoni C, Solinas M, Di Chiara G. Psychostimulant sensitization: differential changes in accumbal shell and core dopamine. Eur $J$ Pharmacol 2000;388:69-76.

25. Rossetti ZL, Isola D, Vry De J, Fadda F. Effects of nimodipine on extracellular dopamine levels in the rat nucleus accumbens in ethanol withdrawal. Neuropharmacol 1999;38:1361-5.

26. Maisonneuve IM, Ho A, Kreek MJ. Chronic administration of a cocaine 'binge' alters basal extracellular levels in male rats: an in vivo microdialysis study. $J$ Pharmacol Exp Ther $1995 ; 272: 652-7$.

27. Diana M, Pistils M, Muntini A, Gesso G. Mesolimbic dopaminergic reduction outlasts ethanol withdrawal syndrome: evidence of protracted abstinence. Neuroscience 1996;71:411-15.

28. Weiss F, Porrino LJ. Behavioral neurobiology of alcohol addiction: recent advances and challenges. J Neurosci 2002;22:3332-7.

29. Wise RA, Newton P, Leeb K, Burnette B, Pocock DJB, Justice JB. Fluctuations in the nucleus accumbens dopamine concentration during intravenous cocaine self-administration in rats. Psychopharmacol 1995;120:10-20.

30. Robinson TE, Berridge KC. The neural basis of drug craving: an incentive-sensitization theory of addiction. Brain Res Rev 1993;18:247-91

31. Self DW, Nestler EJ. Molecular mechanisms of drug reinforcement and addiction. Annu Rev Neurosci 1995;18:463-95.

32. Koob GF, Moal Le M. Drug abuse: hedonic homeostatic dysregulation. Science 1997;278:52-8.

33. Koob GF, Moal Le M. Drug addiction, dysregulation of reward, and allostasis. Neuropsychopharmacol 2001;24:97-129.

34. Westerink BHC, Enrico P, Feimann J, DeVries JB. The pharmacology of mesocortical dopamine neurons: a dual-probe microdialysis study in the ventral tegmental area and prefrontal cortex of the rat brain. J Pharmacol Exp Ther 1998;285:143-54.

35. Xi ZX, Stein EA. Nucleus accumbens dopamine release modulation by mesolimbic $\mathrm{GABA}_{\mathrm{A}}$ receptors: an in-vivo electrochemical study. Brain Res 1998;798:156-65.

36. Ashby CR, Rohatgi R, Ngosuwan J, Borda T, Gerasimov MR, Morgan AE, et al. Implication of the GABA(B) receptor in gamma vinyl-GABA's inhibition of cocaine-induced increases in nucleus accumbens dopamine. Synapse 1999;31:151-3.

37. Xi ZX, Stein EA. Baclofen inhibits heroin self-administration behavior and mesolimbic dopamine release. J Pharmacol Exp Ther 1999;290:1369-74.

38. Giorgetti M, Hotsenpiller G, Froestl W, Wolf ME. In Vivo modulation of ventral tegmental area dopamine and glutamate efflux by local GABA(B) receptors is altered after repeated amphetamine treatment. Neuroscience 2002;109:585-95.

39. Diana M, Brodie M, Muntoni A, Puddu MC, Pillolla G, Steffensen S, et al. Enduring effects of chronic ethanol in the CNS: basis for alcoholism. Alcohol Clin Exp Res 2003;27:354-61.

40. Bonci A, Williams JT. Increased probability of GABA release during withdrawal from morphine. J Neurosci 1997;17:796-803.

41. Kushner SA, Unterwald EM. Chronic cocaine administration decreases the functional coupling of $\mathrm{GABA}(\mathrm{B})$ receptors in the rat ventral tegmental area as measured by baclofen-stimulated ${ }^{35}$ S-GTP $\gamma$ S binding. Life Sci 2001;69:1093-102.

42. Jung BJ, Dawson R Jr, Sealey SA, Peris J. Endogenous GABA release is reduced in the striatum of cocaine-sensitized rats. Synapse 1999;34:103-10.

43. Mansvelder HD. Yin and Yang of VTA opioid signaling. Focus on 'both kappa and mu opioid agonists inhibit glutamatergic input to ventral tegmental area neurons'. J Neurophysiol 2005;93:3046-7.

44. Margolis EB, Hjelmstad GO, Bonci A, Fields HL. Kappa-opioid agonists directly inhibit midbrain dopaminergic neurons. J Neurosci 2003;23:9981-6.

45. Johnson SW, North RA. Opioids excite dopamine neurons by hyperpolarization of local interneurons. J Neurosci 1992;12:483-8.

46. Spanagel R, Herz A, Shippenberg TS. Opposing tonically active endogenous opioid systems modulate the mesolimbic dopaminergic pathway. Proc Natl Acad Sci USA 1992;89:2046-50.

47. Mathon DS, Lesscher HMB, Gerrits MAFM, Kamal A, Pintar JE, Schuller AGP, et al. Increased gabaregic input to ventral tegmental area dopaminergic neurons associated with decreased cocaine reinforcement in $\mu$-opioid receptor knockout mice. Neuroscience $2005 ; 130: 359-67$. 
48. Zapata A, Shippenberg TS. Endogenous к-opioid receptor systems modulate the responsiveness of mesoaccumbal dopamine neurons to ethanol. Alcohol Clin Exp Res 2006;30:592-7.

49. Mitchell JM, Liang MT, Fields HL. A single injection of the kappa opioid antagonist norbinaltorphimine increases ethanol consumption in rats. Psychopharmacol 2005;182:384-92.

50. Kovacs KM, Szakall I, O’Brien D, Wang R, Vinod KY, Saito M, et al. Decreased oral self-administration of alcohol in kappa-opioid receptor knock-out mice. Alcohol Clin Exp Res 2005;29 (Suppl. 5): $730-8$.

51. Han JS. Neurochemical basis of acupuncture. Annu Rev Pharmacol Toxicol 1982;22:193-220.

52. Peets JM, Pomeranz B. CXBK mice deficient in opiate receptors show poor electroacupuncture analgesia. Nature 1978;273:675-6.

53. Yu LC, Han JS. Involvement of arcuate nucleus of hypothalamus in the descending pathway from nucleus accumbens to periaqueductal gray subserving an antinoceptive effect. Int J Neurosci 1989;48:71-8.

54. Takeshige C, Oka K, Mizuno T, Hisamitsu T, Luo CP, Kobori M, et al. The acupuncture point and its connecting central pathway for producing acupuncture analgesia. Brain Res Bull 1993;30:53-67.

55. Wu MT, Hsieh JH, Xiong J, Yang CF, Pan HB, Chen YC, et al. Central nervous pathway for acupuncture stimulation: localization of processing with functional MR imaging of the brain-preliminary experience. Neuroradiology 1999;212:133-41.

56. Pontieri PE, Tanda G, Chiara G Di. Intravenous cocaine, morphine, and amphetamine preferentially increase extracellular dopamine in the shell as compares with the core of the rat nucleus accumbens. Proc Natl Acad Sci USA 1995;92:12304-08.

57. Kendal DE. A scientific model for acupuncture. Amer J Acupunct 1988;17:251-68.

58. Ma SX. Neurobiology of acupuncture: toward CAM. Evid Based Complement Alternat Med 2004;1:41-7.

59. $\mathrm{Ku} \mathrm{YH}$, Zou CJ. Tinggong (SI19), a novel acupoint for $2 \mathrm{~Hz}$ electroacupuncture-induced depressor response. Acupunct ElectroTher Res 1993;18:89-96.

60. $\mathrm{Ku} \mathrm{YH,} \mathrm{Chang} \mathrm{YZ.} \mathrm{Beta-Endorphin-} \mathrm{and} \mathrm{GABA-mediated}$ depressor effect of specific electroacupuncture surpasses pressor response of emotional circuit. Peptides 2001;22:1465-70.

61. Gan P, Cheng JS, Ng YK, Ling EA. Role of GABA in electro-acupuncture therapy on cerebral ischemia induced by occlusion of the middle cerebral artery in rats. Neurosci Lett 2005;383:317-21.

62. Yoshimoto K, Fukuda F, Hori M, Kato B, Kato H, Hattori H, et al. Acupuncture stimulates the release of serotonin, but not dopamine, in the rat nucleus accumbens. Tohoku $J$ Exp Med 2006;208:321-6.

63. Yano T, Kato B, Fukuda F, Shinbara H, Yoshimoto K, Ozaki A, et al. Alterations in the function of cerebral dopaminergic and serotonergic systems following electroacupuncture and moxibustion applications: possible correlates with their antistress and psychosomatic actions. Neurochem Res 2004;29:283-93.

64. Scott S, Scott WN. A biochemical hypothesis for the effectiveness of acupuncture in the treatment of substance abuse: acupuncture and the reward cascade. Am J Acupunct 1997;25:33-40.

65. Russel VA, Lanin MCL, Taljsard JF. Effect of ethanol on $3 \mathrm{H}$-dopamine release in rat nucleus accumbens and striatal slices. Neurochem Res 1988;13:487-92.

66. McBride WJ, Guan XM, Chermet E, Lumeng L, Li TK. Regional differences in the densities of serotonin $1 \mathrm{~A}$ receptors between $\mathrm{P}$ and Np rats. Alcohol Clin Exp Res 1990;14:316, Abstract.

67. McBride WJ, Chermet E, Dyr W, Lumeng L, Li TK. Densities of dopamine D2 receptors are reduced in CNS regions of alcohol preferring P rats. Alcohol 1993;10:387-90.

68. Zhou FC, Bledsce S, Lumeng L, Li TK. Serotonergic immunostained terminal fibers are decreased in selected brain areas of alcoholpreferring P rats. Alcohol Clin Exp Res 1990;14:355, Abstract.

69. Blum K, Cull JG, Braverman ER, Comings DE. Reward deficiency syndrome. Am Sci 1996;84:132-45.

70. Yoshimoto K, Kato B, Sakai K, Shibata M, Yano T, Yasuhara M. Electroacupuncture stimulation suppresses the increase in alcoholdrinking behavior in restricted rats. Alcohol Clin Exp Res 2001;25:63S-68S.

71. Littleton J. Neurochemical mechanisms underlying alcohol withdrawal, Alcohol Health Res World 1998;22:13-24.
72. Schulteis G, Liu J. Brain reward deficits accompany withdrawal (hangover) from acute ethanol in rats. Alcohol 2006;39:21-8.

73. Janiri L, Martinotti G, Dario T, Reina D, Paparello F, Pozzi G, et al. Anhedonia and substance-related symptoms in detoxified substance-dependent subjects: a correlation study. Neuropsychobiol 2005;52:37-44

74. Heinz A, Schmidt LG, Reischies FM. Anhedonia in schizophrenic, depressed, or alcohol-dependent patients-neurobiological correlates. Pharmacopsychiatry 1994;27 (Suppl. 1):7-10.

75. Diana M, Pistis M, Carboni S, Gessa G, Rossetti ZL. Profound decrement of mesolimbic dopaminergic neuronal activity during ethanol withdrawal syndrome in rats: electrophysiological and biochemical evidence. Proc Natl Acad Sci USA 1993;90:7966-9.

76. Kim JH, Chung JY, Kwon YK, Kim KJ, Yang CH, Hahm DH, et al. Acupuncture reduces alcohol withdrawal syndrome and c-Fos expression in rat brain. Am J Chinese Med 2005;35:887-96.

77. Liu S, Zhou W, Liu H, Yang G, Zhao W. Electroacupuncture attenuates morphine withdrawal signs and c-Fos expression in the central nucleus of the amygdala in freely moving rats. Brain Res 2005; 1044:155-63.

78. Robinson TE, Berridge KC. The neural basis of drug craving: an incentive-sentization theory of addiction. Brain Res 1993;18:247-91.

79. Mansour A, Khachataturian H, Lewis ME, Akil H, Watson SJ. Anatomy of CNS opioid receptors. Trends Neurol Sci 1988;11:308-14.

80. Hertz A. Endogenous opioid systems and alcohol addiction. Psychopharmacol 1997;129:99-111.

81. Wang Q, Mao L, Han JS. The arcuate nucleus of hypothalamus mediates low but not high-frequency electroacupuncture analgesia in rats. Brain Res 1990;513:60-6.

82. Wang Q, Mao L, Han JS. Analgesic electrical stimulation of the hypothalamic arcuate nucleus: tolerance and its cross-tolerance to $2 \mathrm{~Hz}$ or $100 \mathrm{~Hz}$ electroacupuncture. Brain Res 1990;518:40-6.

83. Zhao RJ, Yoon SS, Lee BH, Kwon YK, Kim KJ, Shim I, et al. Acupuncture normalizes the release of accumbal dopamine during the withdrawal period and after the ethanol challenge in chronic ethanol-treated rats. Neurosci Lett 2006;395:28-32.

84. Rossetti ZL, Isola D, Vry De J, Fadda F. Effects of nimodipine on extracellular dopamine levels in the rat nucleus accumbens in ethanol withdrawal. Neuropharmacol 1999;38:1361-5.

85. Wang B, Luo F, Xia YQ, Han JS. Peripheral electric stimulation inhibits morphine-induced place preference in rats. Neuro Report 2000;11:1017-20.

86. Wu LZ, Cui CL, Tian JB, Ji D, Han JS. Suppression of morphine withdrawal by electroacupuncture in rats: dynorphin and kappaopioid receptor implicated. Brain Res 1999;851:290-6.

87. Han JS, Wang Q. Mobilization of specific neuropeptides by peripheral stimulation of different frequencies. News Physiol Sci 1992;7:176-80.

88. Han JS, Chen XH, Sun SL, Xu XJ, Yuan Y, Yan SC, et al. Effect of low- and high-frequency TENS on met-enkephalin-Arg-Phe and dynorphin A immunoreactivity in human lumbar CSF. Pain 1991;47:295-8.

89. Han JS, Zhang RL. Suppression of morphine abstinence syndrome by body electroacupuncture of different frequencies in rats. Drug Alcohol Depend 1993;31:169-75.

90. Shi XD, Ren W, Wang GB, Luo F, Han JS, Cui CL. Brain opioidreceptors are involved in mediating peripheral electric stimulationinduced inhibition of morphine conditioned place preference in rats. Brain Res 2003;981:23-9.

91. Ren YH, Wang B, Luo F, Cui CL, Zheng JW, Han JS. Peripheral electric stimulation attenuates the expression of cocaine-induced place preference in rats. Brain Res 2002;957:129-35.

92. Han JS. Acupuncture and endorphins. Neurosci Lett 2004;361:258-61.

93. Guo HF, Tian J, Wang X, Fang Y, Hou Y, Han JS. Brain substrates activated by electroacupuncture of different frequencies (1): comparative study on the expression of oncogene c-Fos and genes coding for three opioid peptides. Brain Res Mol Brain Res 1996;43:157-66.

94. Kreek MJ. Opiate and cocaine addictions: challenge for pharmacotherapies. Pharmacol Biochem Behav 1997;57:551-69. 
95. Glick SD, Maisonneuve IM, Raucci J, Archer S. Kappa-opioid inhibition of morphine and cocaine self-administration in rats. Brain Res 1995;681:147-52.

96. Kuzmin AV, Semenova S, Gerrits MA, Zvartau EE, Van Ree JM. Kappa-opioid receptor blockade with nor-binaltorphimine modulates cocaine self-administration in drug-naïve rats. Eur J Pharmacol 1998;358:197-202.

97. Shi XD, Wang GB, Ma YY, Ren W, Luo F, Cui CL, et al. Repeated peripheral electrical stimulations suppress both morphine-induced CPP and reinstatement of extinguished CPP in rats: accelerated expression of PPE and PPD mRNA in NAc implicated. Mol Brain Res 2004;130:124-33.

98. Vandershuren LJ, De Vries TJ, Wardeh G, Hogenboom F, Schoffelmeer AN. A single exposure to morphine induces long lasting behavioral and neurochemical sensitization in rats. Eur $J$ Neurosci 2001;14:1533-8.

99. Vandershuren LJ, Kalivas PW. Alterations in dopaminergic and glutaminergic transmission in the induction and expression of behavioral sensitization: a critical review of preclinical studies. Psychopharmacol 2000;151:99-120.

100. Robinson TE, Berridge KC. Addiction. Annu Rev Psychol 2003;54:25-53.

101. Yoon SS, Kwon YK, Kim MR, Shim I, Kim KJ, Lee MH, et al. Acupuncture-mediated inhibition of ethanol-induced dopamine release in the rat nucleus accumbens through the $\mathrm{GABA}_{\mathrm{B}}$ receptor. Neurosci Lett 2004;369:234-8.

102. Cousins MS, Roberts DC, de Wit H. GABA(B) receptor agonists for the treatment of drug addiction: a review of recent findings. Drug Alcohol Depend 2002;65:209-20.

103. Kiianmaa K, Hyytia P, Samson HH, Engel JA, Svensson L, Soderpalm B, et al. New neuronal networks involved in ethanol reinforcement. Alcohol Clin Exp Res 2003;27:209-19.

104. Pidoplichko VI, DeBiasi M, Williams JT, Dani JA. Nicotine activates and desensitizes midbrain dopamine neurons. Nature 1997;390:401-04.

105. Leshner AI, Koob GF. Drugs of abuse and the brain. Proc Assoc Am Physicians 1999;111:99-108.

106. Chae Y, Yang CH, Kwon YK, Kim MR, Pyun KH, Hahm DH, et al. Acupuncture attenuates repeated nicotine-induced behavioral sensitization and c-Fos expression in the nucleus accumbens and striatum of the rat. Neurosci Lett 2004:358:87-90.

107. Karst M, Passie T, Friedrich S, Wiese B, Schneider U. Acupuncture in the treatment of alcohol withdrawal symptoms: a randomized, placebo-controlled inpatient study. Addict Biol 2002;7:415-19.

Received November 1, 2006; accepted June 6, 2007 


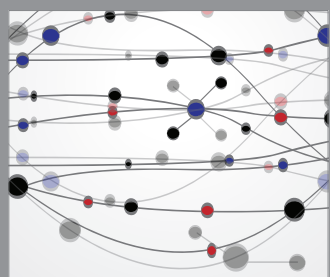

The Scientific World Journal
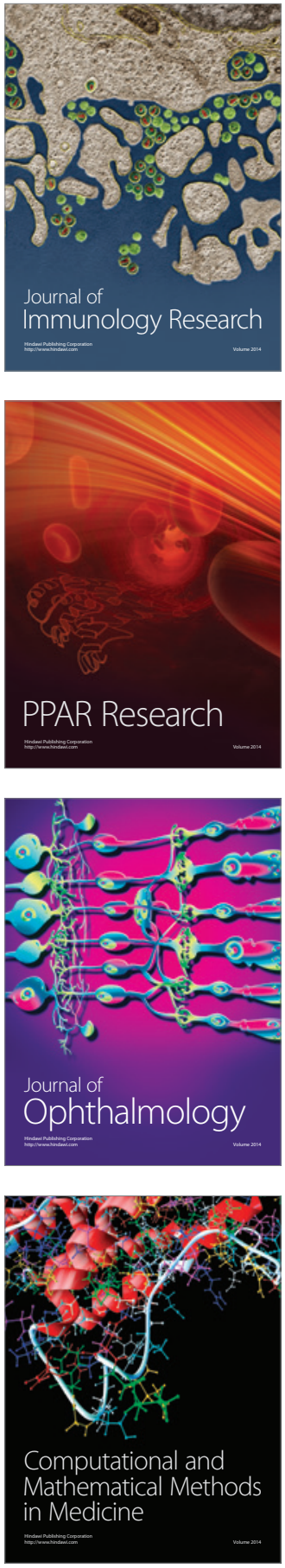

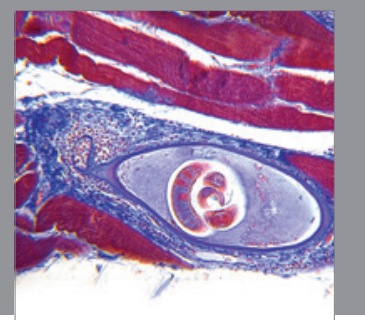

Gastroenterology

Research and Practice
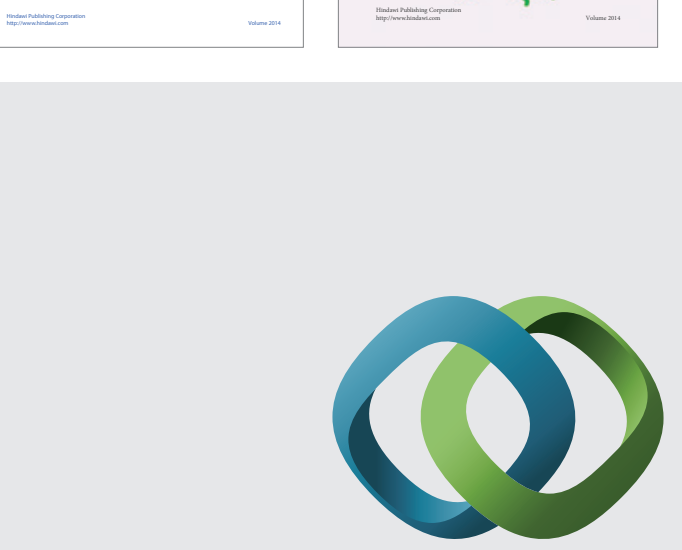

\section{Hindawi}

Submit your manuscripts at

http://www.hindawi.com
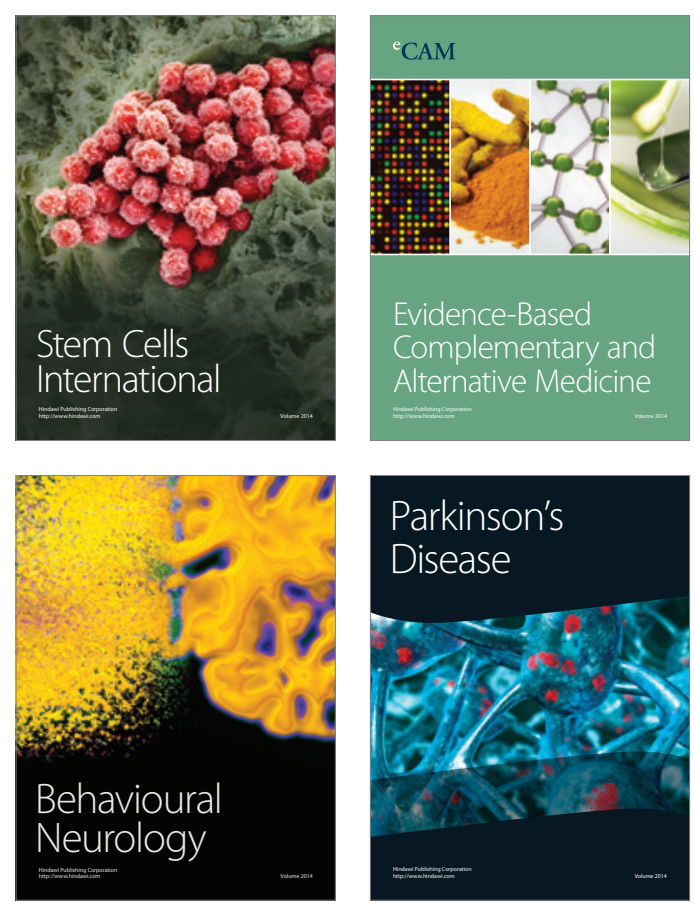

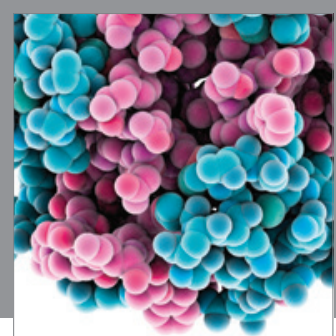

Journal of
Diabetes Research

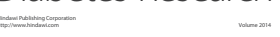

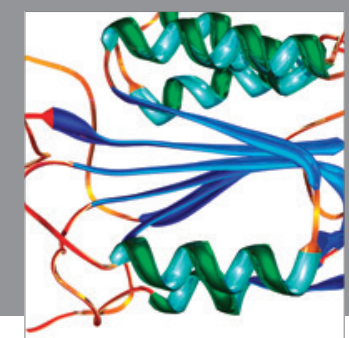

Disease Markers
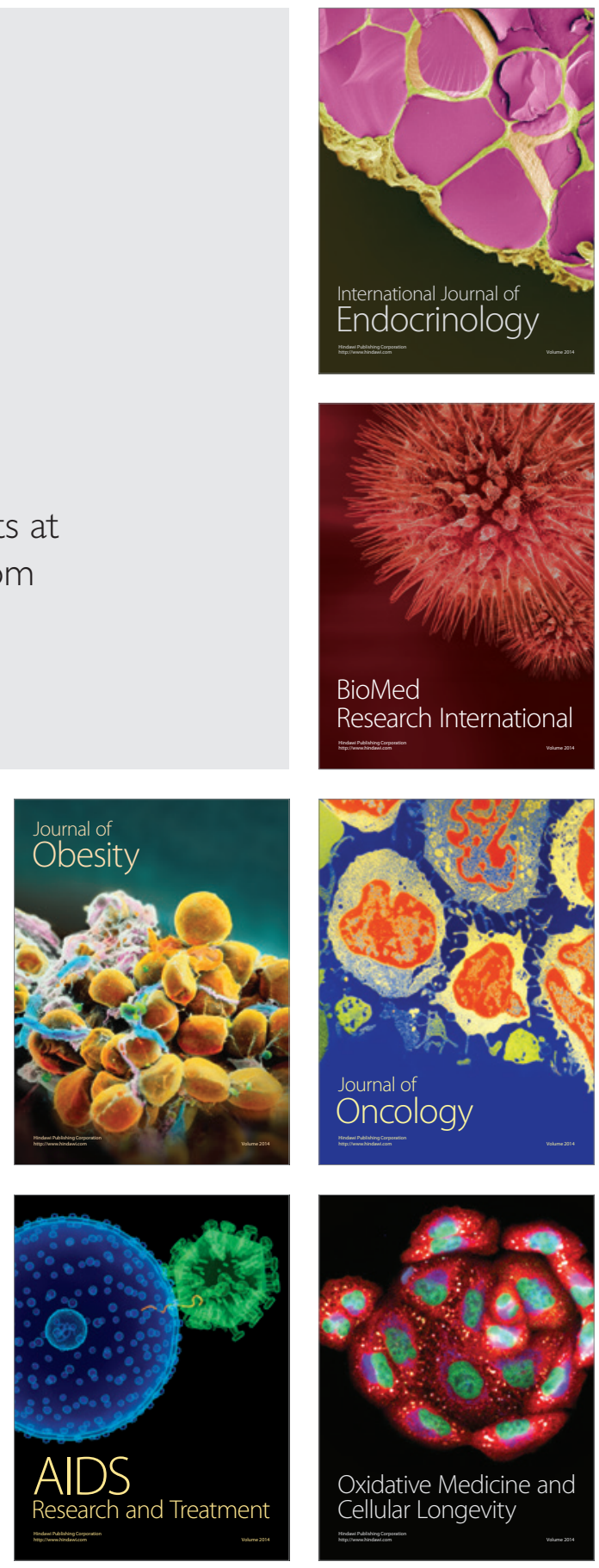